www.jmscr.igmpublication.org Impact Factor 5.244

Index Copernicus Value: 83.27 ISSN (e)-2347-176x ISSN (p) 2455-0450 crossref DOI: _https://dx.doi.org/10.18535/jmscr/v4i11.65

Journal Of Medical Science And Clinical Research

\title{
Effect of Solitary Intra Discal Ozone Injection on Lumbar Disc-Clinical and MRI Evaluation- Prospective Study in 30 Patients
}

\author{
Authors \\ Gidugu Venkata Ramdas (Associate Professor) ${ }^{1}$, Gavinder Singh Bindra (Associate \\ Professor) ${ }^{2}$, Harneet Kaur (Associate Prof) ${ }^{3}$, Amit Mittal (Prof And Head) ${ }^{4}$, \\ Ajay Gehlot (Profesor) ${ }^{5}$, Rajnish Kumar Chaudhry (Senior Resident) ${ }^{6}$, \\ Rakesh Sinha (Senior Resident) ${ }^{7}$, Rikki Singal (Professor) ${ }^{8}$
}

$1,2,5,6,7$ Dept of Neurosurgery, ${ }^{3,4}$ Dept of Radiology, ${ }^{8}$ Dept of Surgery M. M. Institute of Medical Sciences and Research, Mullana, (Distt -Ambala), Pin Code - 133207, Haryana, India

Corresponding Author

Gavinder Singh Bindra

Dept of neurosurgery, M. M. Institute of Medical Sciences and Research, Mullana, (Distt -Ambala) Pin

Code - 133207, Haryana, India Email: singalromy@yahoo.co.in, Mobile no -08059931477

\begin{abstract}
Aim: To objectively evaluate the effect of single percutaneous trans-foraminal ozone injection on the lumbar disc inducing morphological change on Magnetic Resonance Imaging (MRI) of the Lumbar disc and relate to the clinical improvement in patients with contained acute lumbar disc herniation.

Material \& Methods: 30 young patients with acute contained lumbar disc herniation with adequate hydration were treated with single percutaneous injection of ozone via transforaminal route under fluoroscopic guidance. All patients were managed conservatively and followed in Outpatient department for 1 yr with repetition of MRI AT 4 weeks, 6 month and one year from the date of injection. Modified Macnab method was used for assessing clinical outcomes and compared with the changes in serial MRI imaging of every patient.

Results: Successful puncture was obtained in all patients confirmed by fluoroscopy. The MRI imaging in TWI TW2 and STIR sequences were evaluated by radiologist who was blinded to the procedure. The results revealed no observable change in the MRI picture of the targeted lumbar discs attributable in all the three consecutive imaging studies covering a period of 1 year. The clinical outcome showed excellent response in 5cases, good in 5 cases and poor response in 20 cases according to the Macnab criteria at 4 weeks and by 1 year 20 patients had good outcome while 10 cases remained poor. No complications were found throughout this study.

Conclusion: A solitary percutaneous intra discal ozone injection via transforaminal route is safe. No discernible morphological change on serial conventional MRI sequences could be found. Lack of Proof of physical change in the lumbar disc by single injection of ozone questions the role of ozone. The improvement of clinical response is not found to be significant.
\end{abstract}

Keywords: Contained Lumbar disc prolapse, trans foraminal injection, Ozone therapy.

INTRODUCTION $\quad$ literature ${ }^{(1,3-9)}$. Ozone has been demonstrated to

Ozone has been used in lumbar disc disease have a number of beneficial effects in laboratory treatment with variable results reported in animals and experiments ${ }^{(2)}$. The beneficial 
effects range from the inhibition of inflammation, correction of ischemia and venous stasis, and finally inducing a reflex therapy effect by stimulating anti-nociceptor mechanisms ${ }^{(10-13)}$.The safety of therapy has been proven and is being widely used clinically ${ }^{(12-14)}$. Most of the studies used ozone as part of multi modal therapies for lumbar disc herniation and validated the success of this therapy using clinical parameters ${ }^{(15,16)}$. There are case reports of cases showing reduction in size of disc with shrinkage attributed to ozone therapy and CT evaluation of shrinkage of disc volume following intra discal ozone therapy ${ }^{(17)}$. There are no prospective studies looking for exclusive objective evidence of disc changes purely attributable to ozone. The present study is undertaken to seek objective MRI evidence of ozone on the lumbar disc in patients with acute contained lumbar disc herniations undergoing conservative therapy. This prospective randomized study is undertaken to ascertain objective MRI evidence of the effect of ozone on lumbar disc in contained acute lumbar disc disease patients undergoing conservative treatment.

\section{MATERIALS AND METHODS}

Inclusion Criteria: Only patients with symptoms more than 6 weeks history of back pain with radiculopathy without treatment involving any form of intervention. MRI imaging revealing evidence of rupture of annulus in the form of hyper intensity on T2 weighted MRI image with contained disc bulge with evidence of root compression.

Exclusion Criteria: patients with history of recurrent attacks of back pain, chronic back pain, large extruded discs, co morbidity like hyper tension, Diabetes, sero negative and sero positive spondylitis and arthritis. Severe degenerative disc disease with facetal hypertrophy, listhesis and severe bony canal stenosis

Clinical Material: From January 2010 to December 2010, Thirty (30) consecutive symptomatic patients with contained single level Lumbar disc herniations were enrolled in this study. All of them have been evaluated by clinical examination, MRI of Lumbar spine using TW1, TW2 and STIR sequences and dynamic X ray LS spine and the inclusion and exclusion criteria were applied. The disease duration ranged from six weeks to Ten weeks. They were managed on domiciliary and OPD basis with no interventions without relief in symptoms. All of them showed hyper intensity on $\mathrm{T} 2 \mathrm{~W}$ images suggesting annulus rupture and disc bulge in lateral location without extrusion of disc and clinically correlating to the involved disc level. The informed consent approved by the ethical committee taken of the enrolled patients. The patients in whom more than two attempts at needle insertion were required to reach the targeted disc were excluded. There were 22 males and 08 females, aged 22 to 38 years (mean 32 years). 24 patients had contained disc at LV 4-5 disc level and 6 patients at L5-S1 level. The positions of the herniated disc levels were right lateral in 19 of which 16 were male and 03 were female and left lateral in 11 of which were 06 were male and 05 were female. The predominant symptom comprised radicular pain in all (30/30) with radiation along LV4 /LV5 / S1 dermatomes, numbness of the dermatome in 22/30, Low back pain and sacral pain (16/30) and none of them had motor deficits or bowel or bladder involvement. The straight leg raising test was positive in 22/30 cases and negative in $8 / 30$ cases. The conservative treatment comprised analgesics, local Diclofenac ointment application, hot fomentation, bed rest, physiotherapy with short wave diathermy and infra red heat therapy.

The procedure was taken up as a day care procedure under Local Anesthesia with informed consent. Patients were given pre medication with tablet diazepam $10 \mathrm{mg}$ in the morning and a single infusion of Cefotaxime 2gms $1 \mathrm{hr}$ before the procedure after test dose. The patient was taken into the operation theatre and positioned prone on cushions comfortably and draped. C arm with DSA facility (Phillips) and under fluoroscopy guidance the skin was entered with a $21 \mathrm{G}$ beveled 
needle $7.5 \mathrm{~cm}$ away from the mid vertebral line at the respective level and $5 \mathrm{~mL}$ of $1 \%$ lignoocaine was used for local anesthesia of the puncture site and subcutaneous tissues. The involved disc spaces were identified and percutaneous transforaminal puncture through the safety triangle was confirmed in AP and Lateral positions. When no blood or cerebrospinal fluid were drawn by aspiration through the needle, freshly prepared ozone (Ozomed Germany) 5- $\mathrm{mL}$ of $30 \mu \mathrm{g} / \mathrm{mL}$ was then injected slowly. The dye was not injected to avoid confounding effect on disc that could interfere with the MRI findings thus compromising the study.

Post procedure, patients were required to lie on the bed for 6hrs and observed for head ache or any untoward symptoms. They were mobilised over the next $1 \mathrm{hr}$ and after checking vitals were sent home. Patients were reviewed weekly for 1 month in the outpatient department and the efficacy was assessed by modified Macnab criteria ${ }^{[6,7]}$ at 4 weeks, 6 months and 1 year termed Excellent: referred to return to work, but with occasional low back pain or leg pain, no need for painkillers and no physical signs of nerve root injury, and good physical fitness, Good/Fair: referred to general ability to work, with intermittent slight low back pain or radiating pain, no need for painkillers and no physical signs of nerve root injury, and good physical fitness, Poor referred to inability to work, with constant pain, requirement for painkillers, and limited physical activity, with physical signs of nerve root injury.

\section{RESULTS}

All the patients with 30 contained disc bulges with acute annular ruptures underwent successful uneventful intra discal ozone injection. Ozone has been injected into the lumbar disc by entering through the inner margin of facet (18), transforaminal route and free hand technique (1$4,8,10)$. We used the percutaneous transforaminal technique with patient in prone position entering the disc through the safe triangle. Macnab criteria were used to evaluate the patient in terms of severity and improvement thereof ${ }^{(7)}$. Various studies assessed outcome at different intervals 6 months to even 10 years ${ }^{(6,13,14,16,18)}$ this does not differentiate the changes of ongoing degeneration and natural ageing. In order to avoid this bias our study follow up was at 4 weeks, 6 months and 1 year. All patients were followed up for minimum 1 year (12 months to 18 months). The end point was usually clinical improvement in most studies $(4-6,12,16,18)$. since in most of the studies other modalities in addition to ozone like steroids were being used. This has the disadvantage of confounding effect of the other modalities of treatment being used. To avoid this bias our patients were not given any other modality and were treated symptomatically with medication for pain and local application of heat and analgesic ointments. Some studies evaluated change in volume based on CT scan imaging (17) and attributed the reduction to the beneficial effect of Ozone. The duration of 5 yrs can be confounded by the age related changes and CT scan is not as accurate as MRI in calculating disc volume. We used MRI of Lumbar spine to evaluate the changes in disc morphology on TW1, TW2 and STIR sequences. The clinical grading was according to the modified Macnab criteria at 4 weeks which was excellent in 5/30, good/fair in $5 / 30$ and poor in $20 / 30$ suggesting no beneficial effect except in $16.6 \%$.which increased to $33.3 \%$ in Excellent, Good and poor categories at 6 months follow up and at the end of 1 yr 13-3\% remained poor while the MRI images did not reveal any morphological change. This observation did not reveal a direct correlation of ozone injection producing a change in disc morphology effecting clinical improvement.

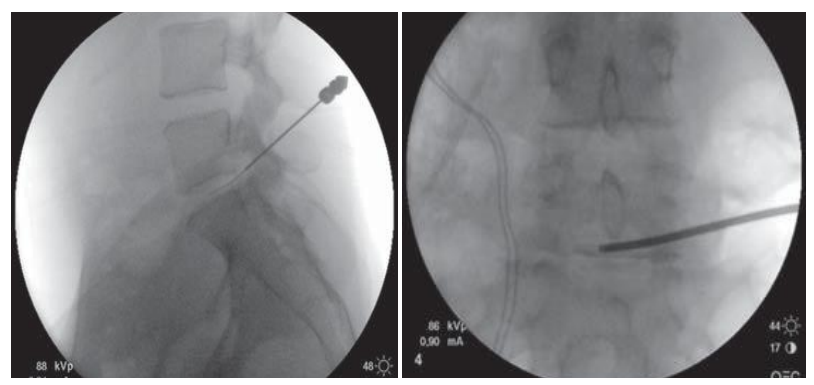



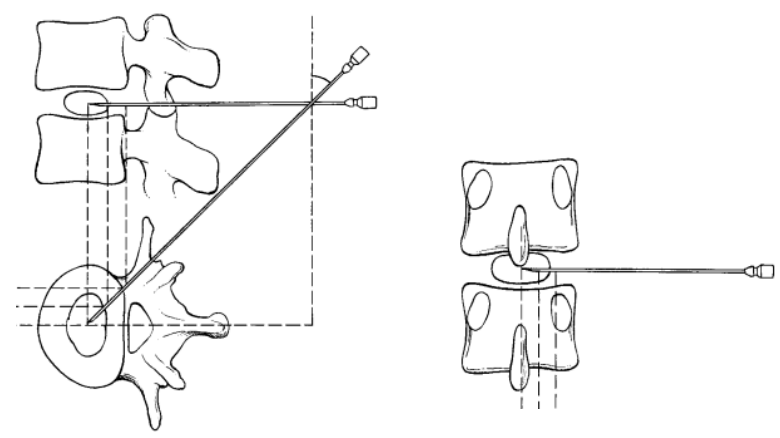

\begin{tabular}{|l|l|}
\hline \multicolumn{2}{|l|}{ Clinical and MRI details-Study } \\
\hline Total number of patients & 30 \\
\hline Sex & \\
\hline Male & $22 / 30$ \\
\hline Female & $08 / 30$ \\
\hline Clinical parameters & \\
\hline Left radicular pain & $11 / 30$ \\
\hline Right radicular pain & $19 / 30$ \\
\hline Back Pain & $16 / 30$ \\
\hline SLR +ve & $22 / 30$ \\
\hline Numbness & $22 / 30$ \\
\hline Bladder and Bowel & $0 / 30$ \\
\hline Motor deficit & $0 / 30$ \\
\hline MRI Features & \\
\hline T2 Hyper intensity of annular rupture & $30 / 30$ \\
\hline Right lateral disc bulge & $19 / 30$ \\
\hline Left Lateral disc bulge & $11 / 30$ \\
\hline LV4-5 & $24 / 30$ \\
\hline LV5-S1 & $06 / 30$ \\
\hline & \\
\hline
\end{tabular}

MAC NAB'S CRITERIA OF OUTCOME

\begin{tabular}{|l|l|l|l|}
\hline Outcome - measure & 04 weeks & 06 months & $01 \mathrm{yr}$ \\
\hline Excellent & 05 & 10 & 12 \\
\hline Good & 05 & 10 & 14 \\
\hline Poor & 20 & 10 & 04 \\
\hline
\end{tabular}

\section{DISCUSSION}

MRI evaluation by conventional TW1, TW2 and STIR sequences is a standard investigation for evaluating disc disease. It is sensitive for evaluating the hydration status, volume assessment and rupture of annulus with disc extrusion and evaluation of compression of the traversing and exiting roots ${ }^{(19)}$. Most of the studies use MRI as the standard modality for diagnosis and follow up of disc degeneration cases (20). The mechanism of action of ozone and its beneficial role in disc disease is well accepted ${ }^{(7,8)}$ Intra discal ozone therapy is widely being practiced in Asian subcontinent and with evidence of efficacy in the laboratory experiments suggesting different mechanisms of action like strong oxidizer of proteoglycans with dehydration and volume reduction, anti inflammatory effect against the aseptic inflammation by glycoprotein and $B$-lipoprotein, released as a result of annular rupture, pressure reduction with improved perfusion of the annulus microcirculation and reduction of nerve edema and all these factors could lead to the pain of disc herniation. Ozone could have an anti-inflammatory effect by releasing antagonistic immune factors and analgesic effect ${ }^{[1,2,8,9]}$ The reason that the disc herniation caused pain was that some inflammatory mediators and enzyme-products (substance $\mathrm{P}$, phospholipase A2, etc.) stimulated the nerve endings on the disc surface and near ligament, the facet articular process and lumbar muscle. Best results were reported in small-or medium-sized disc herniations and contained disc herniations ozone injected into the center of disc through the conventional posterior-lateral route had good efficacy. Andreula in 2003 reported a multicenter study of a large group of patients (300 cases), with excellent and good outcomes of $78.3 \%{ }^{[10]}$. In large disc herniation, the efficacy of reduced compression was limited ${ }^{[11]}$. Where the annulus fibrosus was partially or completely ruptured, the ozone injected could diffuse through the tear into the tissues surrounding the spinal or vertebral disc and ineffective oxidation ${ }^{[12]}$. At the same time, ozone diffusing between the dura mater and hernia could relieve nerve root pain. Also, the efficacy was not significantly different among the 3 levels of herniation including L4-L5, L5-S1. Our study was planned to evaluate the desiccation effect of Ozone on the disc by using MRI sequences of TW1, TW2 and STIR sequences. In none of our patients could a change in disc hydration status be demonstrated. Oxygen-ozone therapy is a minimally invasive treatment option for lumbar disc herniation that exploits the biochemical properties of a gas mixture of oxygen and ozone. While the literature reveals only equivocal level II evidence of intra discal ozone injection therapy as part of 
multimodal therapy that has failed to respond to conservative management, there is no class I evidence demonstrating the beneficial effect in human patients undergoing this treatment. The present study was performed with the sole purpose of demonstrating the effect of ozone on the disc of symptomatic patients with ruptured annulus fibrosis. The study failed to show convincing evidence in the form of physical change in disc morphology consequent to exposure of Ozone on MRI imaging. None of the thirty patients in the study revealed any change in the MRI appearance in the follow up studies at 4 weeks and 6 months and 1 year. The clinical improvement in this study revealing excellent category of 05 , Good and fair in 05 and poor response in 20 at 4 weeks and progressing to 12 excellent, 14 good and 04 poor. Based on Macnab criteria one cannot differentiate between the placebo effect and natural course of disease from the sole definitive beneficial effect of ozone. It can well be argued that the ozone while not producing a physical change in the disc morphology has an anti inflammatory effect and by oxidant properties interferes with the pain generating mechanisms in the pathophysiology of pain in annular rupture. A more focused and elaborate study with more numbers and with evidence on histopathological examination of disc material may be required to confirm the effect of ozone or the lack of it on disc morphology.

\section{CONCLUSION}

This study failed to show evidence of physical change in the targeted disc subsequent to single exposure of $5 \mathrm{cc}$ of 30 micrgms of ozone on serial MRI evaluation for 1 year. The study proved per cutaneous transforaminal intra discal ozone injection in symptomatic patients with contained annular lumbar disc rupture to be safe with no untoward side effects thereof. The study emphasizes the need for a more elaborate prospective study to define the role of ozone and confirm and optimize ozone in the management of prolapsed Lumbar disc.

\section{REFERENCES}

1. He XF, Yu ZJ, Teng GJ, Li YH, Zeng QL, Chen Y, Lu W,Kong WD, Xu XL, Li L, Peng J. Treatment of lumbar disc herniation by using percutaneous intradiscal and paraspinal space injection of O2-O3 mixture. Zhonghua Fangshexue Zazhi 2003; 37: 827-830

2. Yu ZJ, He XF, Chen Y, Zeng QL, Liu ZH, Zhao ZQ, Lu Y, Li YH. Percutaneous intradiscal ozone (O3)-injection: an experimental study in canines. Zhonghua Fangshexue Zazhi 2002; 36:366-369

3. Hua SY, Xu RL, Qi B. Clinical evaluation of lumbar disc herniation treated by percutaneous lumbar discectomy associated with $\mathrm{O} 3$ injection. Jieru Fangshexue Zazhi 2005; 14: 281-283

4. Xiao YY, Meng XD, Li JL, Chen C. CT guided $\mathrm{O} 3$ injection for the treatment of lumbar disc herniation. Zhongguo Jieru Yingxiang Yu Zhiliaoxue 2005; 2: 245248

5. He XF, Li YH, Chen HW, Lu W, Chen Y, Zeng QL, Zhao JB,Xu XL, Peng J, Shen P. Intradiscal injection of $\mathrm{O} 2-\mathrm{O} 3$ to treat lumbar disc herniations: clinical therapeutic effect analysiswith 600 cases. Zhongguo Jieru Yingxiang Yu Zhiliaoxue 2005; 2:338-341

6. Nerubay J, Caspi I, Levinkopf $M$. Percutaneous carbon dioxide laser nucleolysis with 2-to 5-year followup. Clin Orthop Relat Res 1997; 45-48

7. Macnab I. Negative disc exploration. An analysis of the causes of nerve-root involvement in sixty-eight patients. J Bone Joint Surg Am 1971; 53: 891-903

8. Muto $\mathrm{M}$, Andreula $\mathrm{C}$, Leonardi $\mathrm{M}$. Treatment of herniated lumbar disc by intradiscal and intraforaminal oxygenozone (O2-O3) injection. J Neuroradiol 2004; 31: 183-189

9. Arena M, Savoca G, Papa R. Paravertebral percutaneous $\mathrm{O} 2-\mathrm{O} 3$ injection integrated 
treatments in the management of lunbar herniated disc and disc-joint compression. Ital J Ozono Ther 2003; 2: 39-44

10. Andreula CF, Simonetti L, De Santis F, Agati R, Ricci R, Leonardi M. Minimally invasive oxygen-ozone therapy for lumbar disk herniation. AJNR Am J Neuroradiol 2003; 24: 996-1000

11. Velio Bocci, Emma Borrelli, Lacopo Zanardi, Valter Travagli The usefulness of ozone treatment in spinal pain. Drug Des Devel Ther. 2015;9:2677-2685.

12. Borrelli E Mechanism of action of oxygen ozone therapy in the treatment of disc herniation and low back pain. Acta Neurochir Suppl. 2011;108:123-5.

13. Magalhaes, F.N., Dotta, L., Sasse, A., Teixera, M.J., Fonoff, E.T. Ozone therapy as a treatment for low back pain secondary to herniated disc: a systematic review and meta-analysis of randomized controlled trials. Pain Phys. 2012;15:E115-E129.

14. Steppan, J., Meaders, T., Muto, M., Murphy, K.J. A metaanalysis of the effectiveness and safety of ozone treatments for herniated lumbar discs. J VascInterv Radiol. 2010;21:534-548.

15. Andreula $C$, Muto $M$ and Leonardi $M$ : Interventional spinal procedures. Eur $\mathrm{J}$ Radiol 50: 112-119, 2004.

16. Staal JB, de VetHCW, Hildebrandt J, Nelemans P.: Injection therapy for subacute and chronic low-back pain(review) The cochraine collaboration published in The cochraine library 2011, Issue 2

17. Thomas Lehnert, MDNagy N.N. Naguib, MDSebastian Wutzler, MDNour-Eldin A. Nour-Eldin, MD, Ralf W. Bauer, MDJosef Matthias Kerl, MDThomas J. Vogl, MDJoern O. Balzer, MD. Analysis of Disk Volume before and after CT-guided Intradiscal and Periganglionic OzoneOxygen Injection for the Treatment of
Lumbar Disk Herniation JVIR Volume 23, Issue 11, Pages 1430-1436, Novemb2012.

18. Wei Lu, Yan-Hao Li, Xiao-Feng He Treatment of large lumbar disc herniation with percutaneous ozone injection via the posterior-lateral route and inner margin of the facet joint World J Radiol 2010 March 28; 2(3): 109-112 ISSN 1949-8470

19. Chawalparit O, Churojana A, Chiewvit P, Thanapipatsir S, Vamvanij V, Charnchaowanish $\mathrm{P}$. The limited protocol MRI in diagnosis of lumbar disc herniation $\mathrm{J}$ Med Assoc Thai. 2006 Feb;89 (2):182-9.

20. Mikhael MA, Ciric IS, Kudrna JC, Hindo WA. Recognition of lumbar disc disease with magnetic resonance imaging. Comput Radiol. 1985 Jul-Aug. 9(4):213-22. 